\title{
A United Centre?
}

The British Association of Sport and Medicine has long pursued the ideal of a National Sports Medicine Institute to bring sport and medicine closer together. For this it quadrupled its subscriptions, professionalized its Journal and organization and radically increased its educational commitments, helped by the Sports Council's three year funding of a full-time Education Officer.

BASM had, in 1966, set up jointly an Institute of Sports Medicine hoping for an academically acceptable linked unit. Sadly, that historic mission was betrayed, to all our detriment. The foundation of the London Sports Medicine Institute in 1986, again involving BASM officers, led to a remarkable expansion of services through the friendly partnership of BASM and LSMI. We can now go ahead and set up a National Sports Medicine Institute.

The proverbial man from Mars might cough politely and say "But you seem to have most of it here already". We do. So let us now be bold and reinforce the combined and symbiotic resources of BASM and LSMI. At no new cost, we could link the national membership association with the national academic institute which LSMI can choose to become when its London restrictions expire at the end of its five year foundation grant. The NSMI would inherit offices (including, finally, a home for BASM), the library and nub of a national reference centre as well as LSMI's local and BASM's national teaching programmes. As these functions are already performed, we need initially only the formal name change and perhaps some formalization of BASM/LSMI's currently happy but informal relationship.

Some want an NSMI to be BASM writ large, with clinics, but this is unrealistic. Firstly, a medical institute is required by company law to have a prescribed academic board membership, ipso facto independent of the sort of democratic management a membership association should have. This secures the independence of academic standards, now sorely assailed in UK. Appropriate executive cross-representation is the time-honoured way of securing the interests of both - and other - parties.

Secondly, in the present state of the National Health Service, it is difficult to predict with certainty the clinical outcome of the latest reorganizational chaos. Clinical services are extremely expensive. Athletes are young, poor and under-insured. Until the N.H.S. gets its new act and dogma in order, there is no mechanism in place for the fee transfers to outside agencies on a scale that would encourage massive private sports clinic investment.

BASM's list of clinics, shortly to be published as a supplement to this Journal, will be refined into a 'good clinic guide', whose ultimate accolade could be the bestowing of "NSMI Affiliated Clinic" status. NSMI would thus promote high standards, backed by the advantages of coordinated national networking which would help the athlete and introduce at last the advantages of audit and standard setting into clinical sports medicine.

A question to be resolved concerns the role of other organizations, including the British Olympic Association in this system. The B.O.A. Medical Centre already works with the nationwide scientific fitness testing scheme. The B.O.A.'s only generally accepted role is currently in the servicing of the Olympic requirements for those who participate. Other major sports, including cricket, rugby and soccer are independent. Perhaps the vast resources and goodwill of the Olympic movement could see a major strategic input into the high prestige area of elite-level sports medicine which would fit in neatly with the NSMI's wider responsibility to all sport, Olympic or not.

It would be a major tragedy if Britain failed to learn from history and sacrificed for a second time its athletes on the altar of factional differences. 